\title{
MATERIAL ANALYSIS OF DEGRADED STEAM TURBINE ROTOR
}

This article deals with structural, fractographic and non-destructive analysis of a defective rotor made of 26NiCrMoV14-5 steel and assessment of possible technological failures resulting in the occurrence of cracking and subsequent defects. Metallographic analysis of the microstructure and evaluation of the steel metallographic purity were executed, including analysis of inclusions present and ultrasonic testing. Attention was paid to fractographic analysis of fracture areas. Degradation possibilities were monitored in relation to technological failures. The aim was to elucidate the cause of the rotor defect hindering its operational use.

Keywords: Material analysis, production technology, metallurgical purity, hydrogen embrittlement, degradation.

\section{Introduction}

An important factor, indisputably affecting steel quality, is its metallurgical purity. Therefore, great attention should be paid to the presence of inclusions in steel. As known generally, formation and composition of inclusions mostly derives from chemical composition of steel and the way of its deoxidation and alloying [1 and 2]. Moreover, the type and character of inclusions significantly depends on oxygen content and treatment of inclusions during steel processing outside the furnace by means of calcium [3].

Contamination of steel by excessive rate of inclusions constitutes a significant cause leading to initiation of degradation processes, and thus to the product deterioration [4 and 5]. To achieve the required purity, it is also necessary to observe the correct production technology so that during both the production process and the steel treatment there are no defects occurring on the pertinent equipment, which would also result in impaired steel purity as well as quality. In extreme cases, the quality impairment may result even in the product degradation.
Examinations were performed on samples taken from the rotor forging of steel $26 \mathrm{NiCrMoV} 14-5$ for a steam power plant, made from an ingot of the weight of 70 tons. After primary processing in an electric arc furnace, the object molten steel for the turbine rotor was transported in a steelmaking ladle for processing outside the furnace in the ASEA SKF device. At the bottom of the ladle, there is an eccentrically installed porous block on which an argon inlet is installed. This provides for steel flushing, setting it in vertical motion. In this way, the melt in the ladle is properly homogenized, inclusions flown out and the melt degassed simultaneously [6]. To check the internal product quality, ultrasonic and magnetic tests are stipulated for the final product.

\section{Material and experimental technique}

The rotor was subjected to ultrasonic test which indicated inadmissible defects. For the actual material analysis, a plate of approximate width of $20 \mathrm{~mm}$ was cut out across

Chemical composition of the steel melting and chemical composition of the experimental plate at the place of defects, in comparison with the production specification of $26 \mathrm{NiCrMoV} 14-5$ steel in wt. $\%,{ }^{*}$ ppm

\begin{tabular}{|c|c|c|c|c|c|c|c|c|c|c|}
\hline & $\mathrm{C}$ & Mn & $\mathrm{Si}$ & $\mathbf{P}$ & $\mathrm{S}$ & $\mathrm{Cr}$ & $\mathrm{Ni}$ & Mo & V & $\mathbf{H}^{*}$ \\
\hline Melting & 0.26 & 0.37 & 0.20 & 0.003 & 0.007 & 1.61 & 3.44 & 0.40 & 0.07 & 1.20 \\
\hline Experimental plate & 0.32 & 0.39 & 0.23 & 0.004 & 0.001 & 1.66 & 3.43 & 0.42 & 0.008 & - \\
\hline Specification & $\begin{array}{c}0.24 \\
- \\
0.28\end{array}$ & $\begin{array}{c}0.35 \\
- \\
0.40\end{array}$ & $\begin{array}{c}0.15 \\
- \\
0.25\end{array}$ & $\begin{array}{c}\text { Max } \\
0.007\end{array}$ & $\begin{array}{l}\text { Max } \\
0.02\end{array}$ & $\begin{array}{c}1.55- \\
1.70\end{array}$ & $\begin{array}{c}3.40 \\
- \\
3.60\end{array}$ & $\begin{array}{c}0.40 \\
- \\
0.45\end{array}$ & $\begin{array}{c}0.07 \\
- \\
0.10\end{array}$ & 0.80 \\
\hline
\end{tabular}

\footnotetext{
* ${ }^{1}$ Petr Jonsta, ${ }^{2}$ Irena Vlckova, ${ }^{1}$ Zdenek Jonsta, ${ }^{3}$ Roman Heide

IVSB-Technical university of Ostrava, Faculty of Metallurgy and Materials Engineering, Czech Republic

${ }^{2}$ RMTSC, Material \& Metallurgical Research Ltd., Ostrava, remote site VUHZ, a. s., Dobra, Czech Republic

${ }^{3}$ Favea Europe, s. r. o., Prague, Czech Republic

E-mail: petr.jonsta@vsb.cz
} 
the rotor body over the area with the defects indicated (Fig. 1). The actual experimental samples were prepared from it.

Table 1 shows comparison of the melting chemical composition of the object steel 26NiCrMoV14-5 with the production specification of the given steel and the chemical composition of the experimental plate.

The metallographic analysis was executed by means of the OLYMPUS GX51 light microscope; the electron microscopic analysis was executed on the Quanta FEG 450 scanning electron microscope with the TRIDENT-APEX 4 microanalytic system.

\section{Results and discussion}

During the ultrasonic test, inadmissibly large indications, bigger than $2 \mathrm{~mm}$, were detected in the rotor examined around the forging axis on the head side of the ingot. The defective areas are encircled on the experimental plate (Fig. 1). In sum, 35 inadmissibly large indications of Dn 2.1 to $2.6 \mathrm{~mm}$ were found. Most of them were of Dn 2.1-2.2 mm, three of the indications had the dimension of $\mathrm{Dn}=2.4 \mathrm{~mm}$, one of them had the dimension of $\mathrm{Dn}=2,6 \mathrm{~mm}$. All indications were located at the depth of 427 - $558 \mathrm{~mm}$ below the surface of the rotor body. Almost the entire half of the rotor on the ground side of the ingot was without any inadmissible defects.

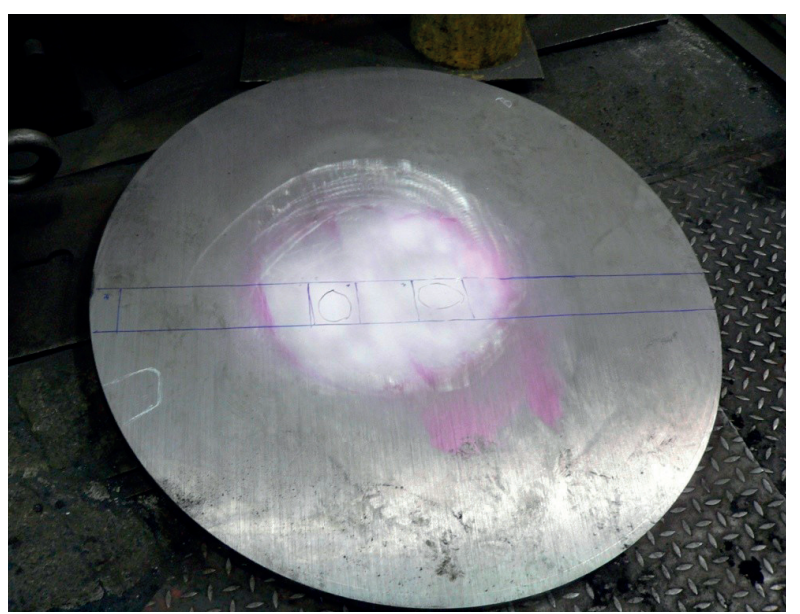

Fig. 1 Experimental plate

A Baumann print was executed on the rotor body cross section. Its appearance confirmed very low sulphur content in the steel (see Table 1). The occurrence of manganese sulphides was very low, particles were small, and sulphur did not concentrate at the macroscopic level very much either in the ingot head part or in the segregates where the segregation of elements is most evident.

Macrostructual analysis proved the presence of dendritic structure and dendritic segregation within the entire cross section of the forging machined, including its peripheral surface layers. The individual dendrites were relatively fine; their size ranged about $1 \mathrm{~mm}$ and their arrangement was chaotic. To the depth of approx. $200 \mathrm{~mm}$ below the surface, the dendritic segregation was manifested less intensively than in the other parts of the forging cross section (Fig. 2). It was the areas of more evident segregations in which the above mentioned defects were detected. Moreover, a distinctive phenomenon in these areas was the spots of existence of stem segregates. The chaotically arranged dendrites and cross sections of stem segregations, not exceeding the size of $2 \mathrm{~mm}$, are then presented in Fig. 3 .

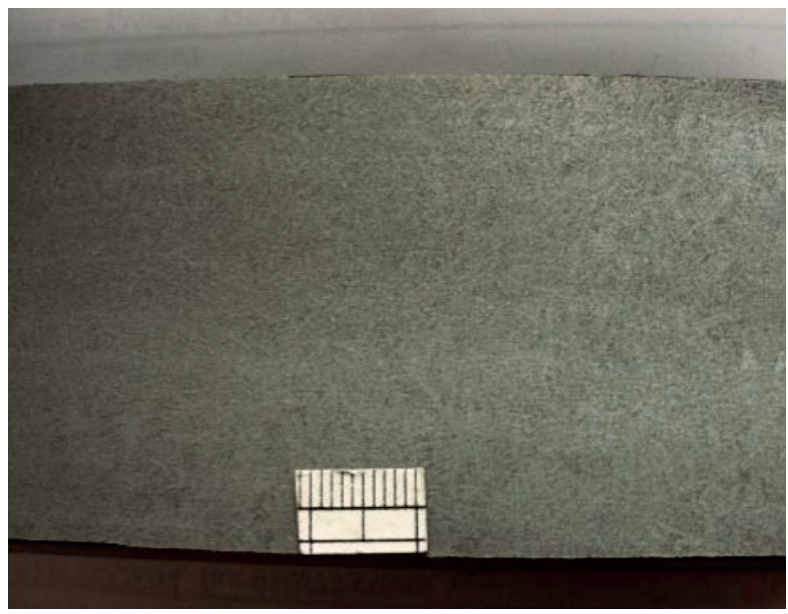

Fig. 2 Macrostructure below the surface

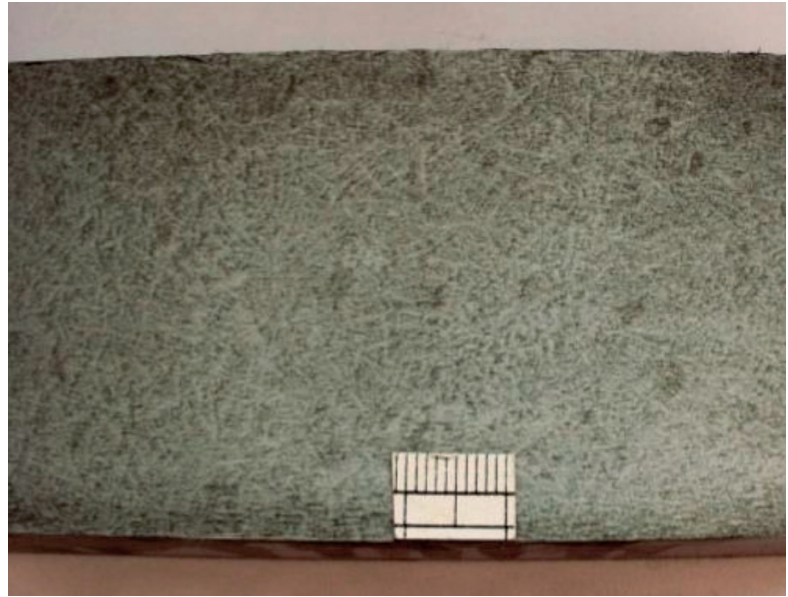

Fig. 3 Macrostructure with segregates

Throughout the entire volume, the analyzed steel had a fine-grained microstructure made of tempered heterogeneous bainite, which shows evidence of both high hardenability of the steel used for the rotor manufacture and the optimum hardening mode. The microstructure of the basic metal matrix was mostly of the acicular character (Fig. 4). More distinctive 
dendritic segregations in higher depths below the rotor surface are presented in Fig. 5.

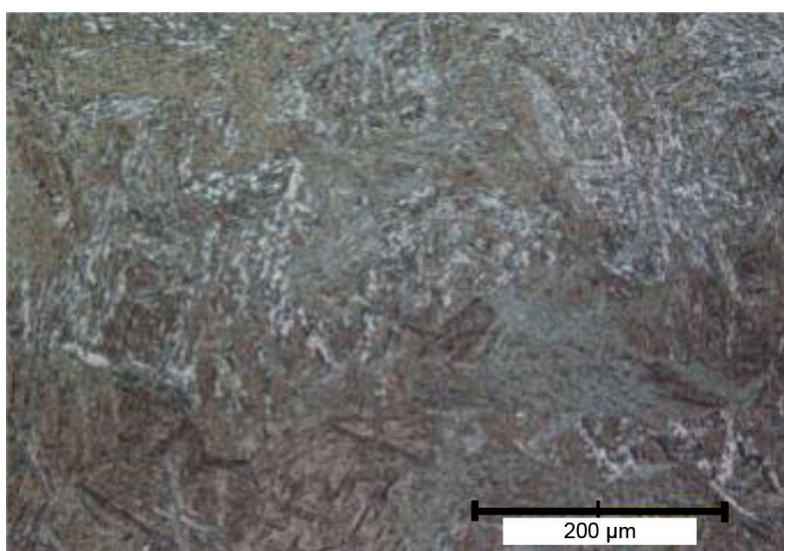

Fig. 4 Microstructure of the basic metal matrix

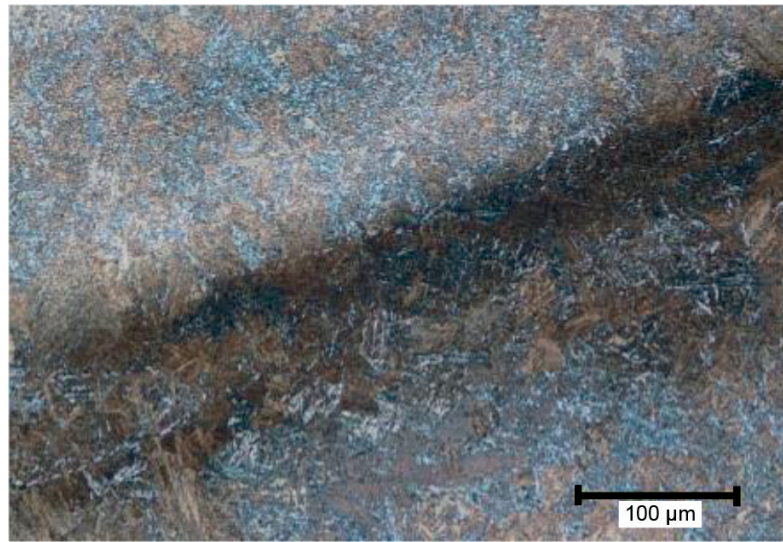

Fig. 5 Macrostructure with segregates

In addition to bainite, these areas, characterized by lower carbon content, probably contain probainitic acicular ferrite. The occurrence of carbides of globulitic morphology bears evidence of high tempering temperature after hardening [7].

In the zone located approximately at one half of the rotor body radius, that is, in the middle of the distance between the rotor surface and its axis, sporadic stem segregates were detected. They included clusters of manganese sulphides and sharp-edged pink-coloured titan carbonitride particles arranged in rows - see Fig. 6. In the microstructure, the stem segregate spots appear dark as a result of the locally increased carbon content and thus a higher amount of fine globulitic carbides in this area [7].

At the points of inadmissible ultrasonic findings around the forging axis, discontinuities were detected in the form of coarse inclusions, rounded elongated cavities and course inclusions situated inside the cavities. The length of the largest of these discontinuities at the metallographic samples exceeded $2 \mathrm{~mm}$, as indicated above. The coarse inclusions formed conglomerates of non-metallic particles the dominant constituent of which was brittle sharp-edged complex oxides on the basis of $\mathrm{MgO} \cdot \mathrm{Al}_{2} \mathrm{O}_{3} \cdot \mathrm{CaO}$. An example of a complex inclusion at the place of ultrasonic indication is presented in Fig. 7. Besides these inadmissible discontinuities, tiny oxidic and oxysulphidic inclusions of micrometric dimensions as well as titan nitrides or carbonitrides were analyzed (Fig. 8).

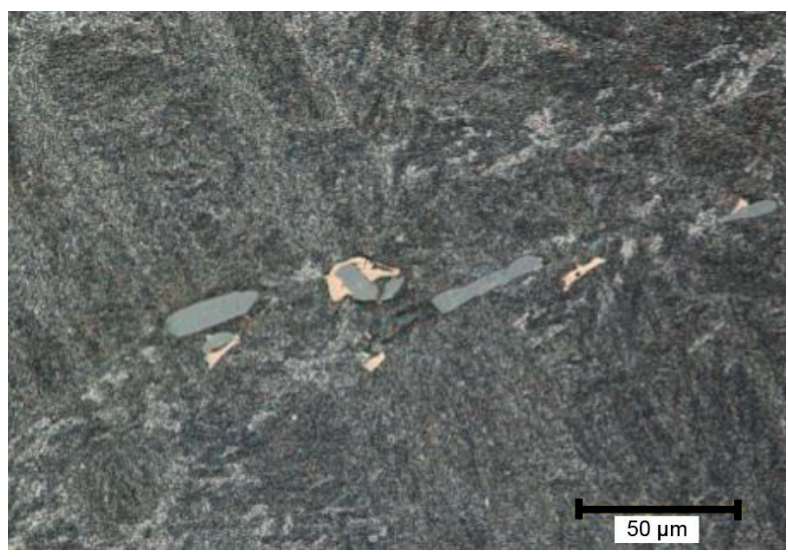

Fig. 6 Microstructure with inclusions

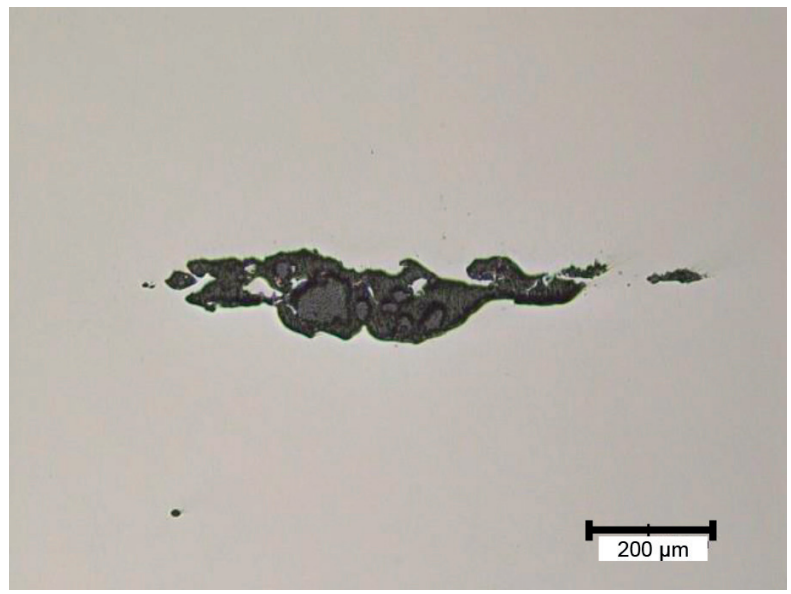

Fig. 7 Complex inclusion

The forging microstructure in the area where the defects occur consisted of tempered bainite; no visible structural changes were ascertained around the defects [8].

The following Fig. 9 presents the morphology of brittle transcrystalline cleavage. This was typical of substantial part of the fracture area. The fine cleavage facets are characteristic of the bainitic structure detected earlier by the metallographic analysis.

The fracture area of tensile tests featured defective zones which are typical as the so-called "fish eyes" (Fig. 10). The fish eye morphology is characteristic of defects resulting from hydrogen action [9]. This proposition is supported by the analysis of chemical composition. Apparently, the hydrogen content reached the value of $1.2 \mathrm{ppm}$, as opposed to the maximum admissible $0.8 \mathrm{ppm}$ (see Table 1). Another 


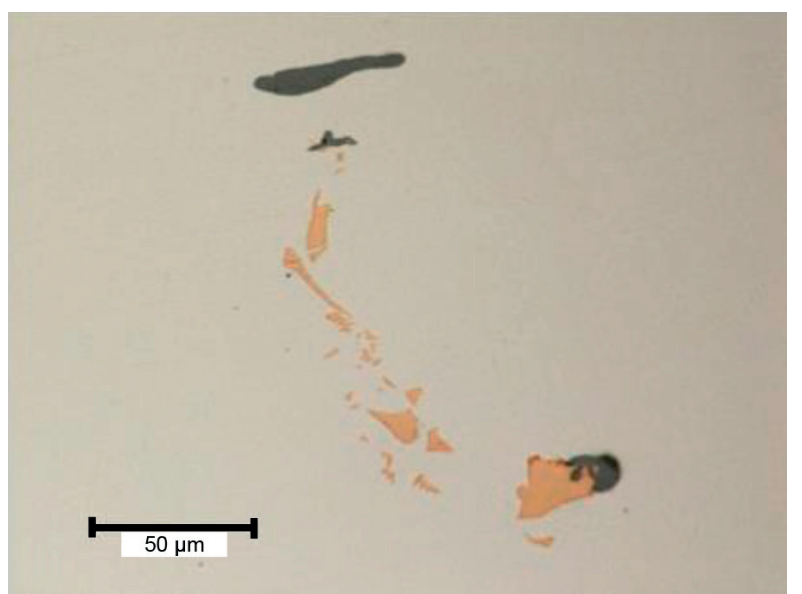

Fig. 8 Ti nitride and Mn sulphide

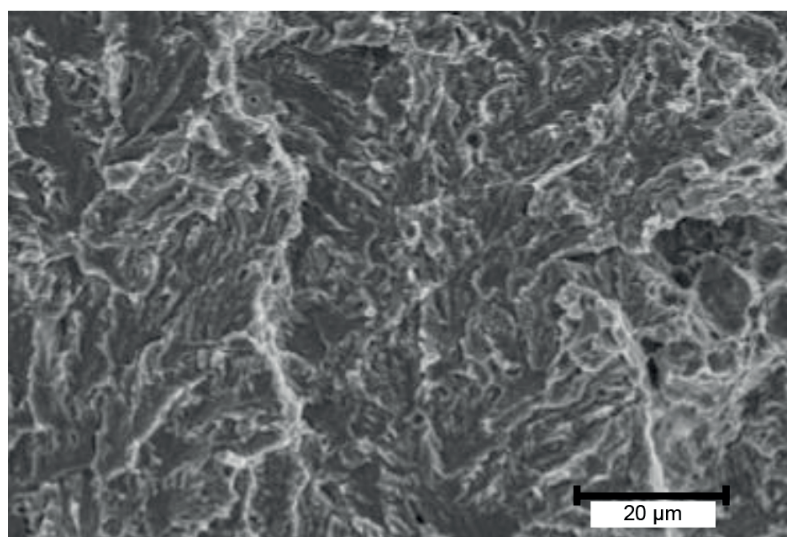

Fig. 9 Brittle transcrystalline cleavage

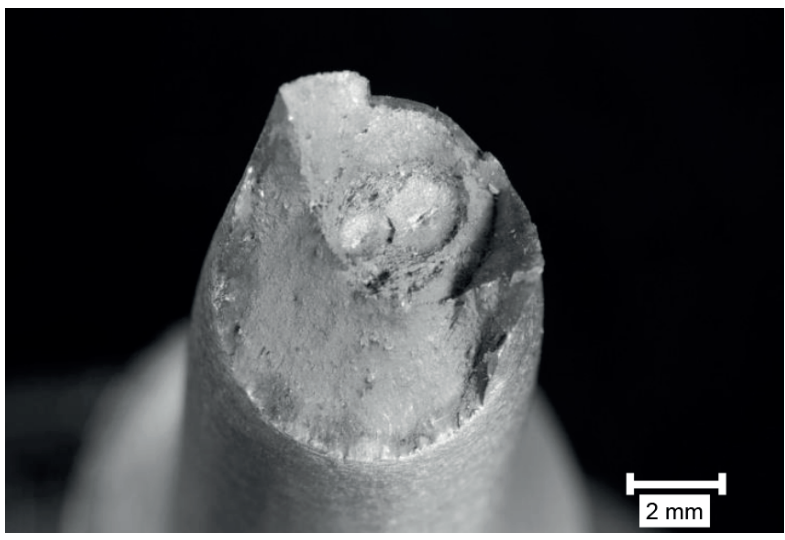

Fig. 10 Fish eyes in the fracture area

significant fact is the presence of intercrystalline failure on the fracture area in the vicinity of the fish eyes, as apparent in Fig. 11.

Figures 12 and 13 present inclusions in these defective zones of fracture areas. Figure 12 documents oxidic and oxysulphidic inclusions arranged in lines in the centre of the defective zone of the fracture area, Fig. 13 then shows these inclusions in detail.

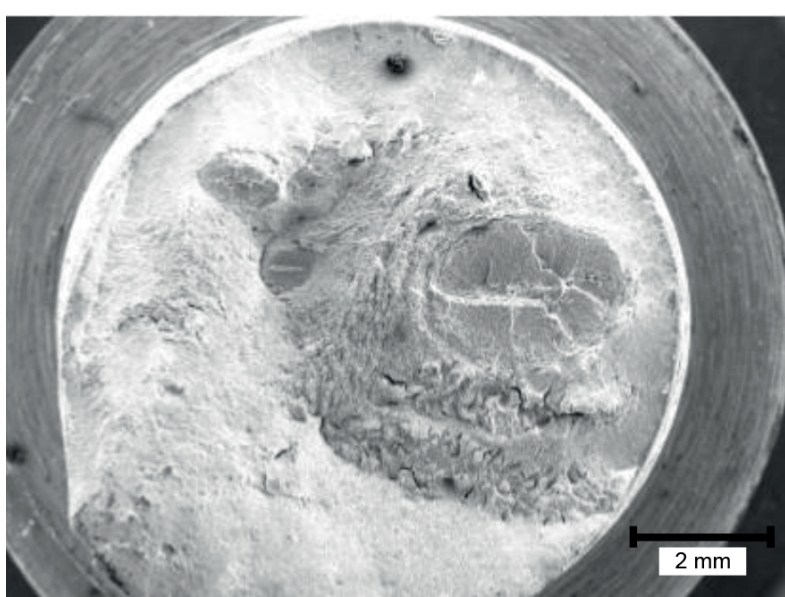

Fig. 11 Defective area with intercrystalline failure

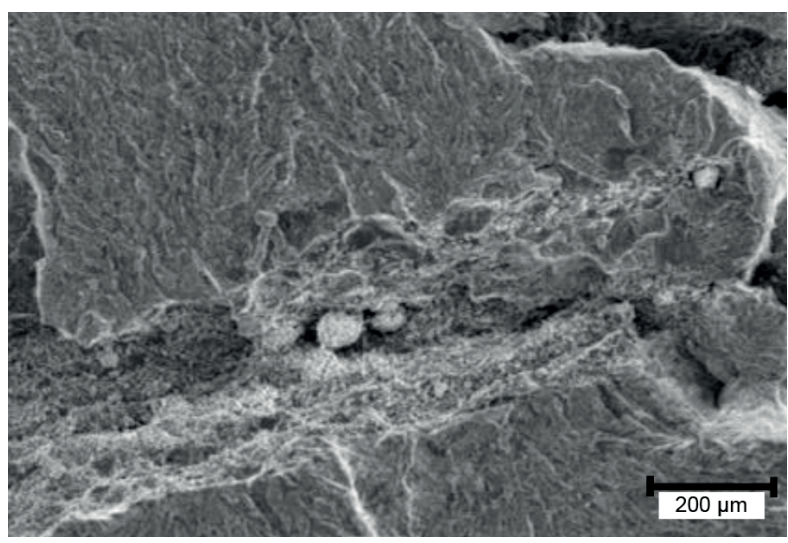

Fig. 12 Inclusions in rows

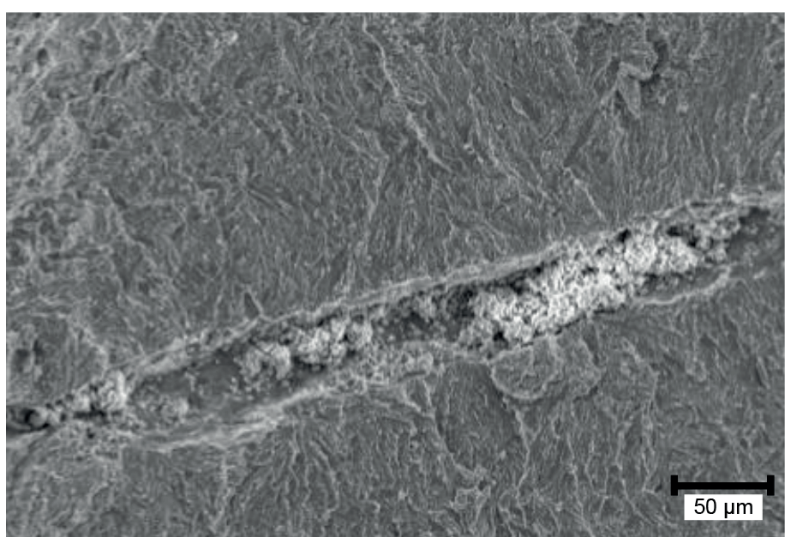

Fig. 13 Detail of inclusions in rows

To the processing outside the furnace, as indicated above, the steel was transported in a ladle equipped in the bottom with an eccentrically installed porous block with argon inlet for steel flushing. Blasting of this inert gas sets the steel in vertical motion, which results in its proper homogenization in the ladle. Simultaneously, the inert gas bubbles cause flow-out of inclusions 
and bind gases, such as hydrogen and oxygen, which leads to degassing of the melt.

After the ladle had been emptied, the porous block was found to be cracked over its entire width and completely clogged with steel. This caused the absence of inert gas flowing into the melt and thus also of the actual flushing process and melt movement in the vertical direction. Likewise, its proper degassing was hindered. The systems of steel movement during continuous flushing with argon, however, contribute to the high grade of its micropurity.

Therefore, one can state that the defect in the technological process, which was the broken porous block, hindered proper flushing and movement of the melt, which was degassed insufficiently at the same time. This resulted in both a substantial increase in the hydrogen content as well as increased content of oxygen. The increase in the hydrogen content by approx. $50 \%$ above the maximum admissible level led to hydrogen embrittlement taking effect in typical fish eyes and intercrystalline steel failure. The increased oxygen content resulted in substantial increase of the steel inclusion rate, which led to significant deterioration of its micropurity.

Therefore, the broken porous block of the secondary metallurgy equipment was the technological cause of the radical decrease of the object steel quality and the subsequent degradation of the rotor made from it.

\section{Conclusions}

Within the paper submitted, detailed material analysis was executed of the steam power plant rotor made of $26 \mathrm{NiCrMoV} 14-5$ steel. The aim was to assess the cause of its degradation. Particular attention was paid to the issue of metallurgical purity of the steel, which presents the decisive factor in the area of its quality.

On the basis of detailed material analysis, one can state that the secondary metallurgy equipment of ASEA SKF, which contains the inductive stirrer, is not efficient enough in the case of a defect in the porous block for melt flushing with inert gas. In the event of the above discussed defect, the melt is homogenized sufficiently, as apparent from, for instance, the chemical analysis; with regard to the volume of exothermic inclusions, however, it is not sufficient for production of steel with a high demand on internal quality. Likewise, the degree of degassing, despite the deep vacuum, does not achieve the required level. Owing to the increase in the hydrogen content together with the exothermic inclusions, the steel produced was deteriorated; in our case, even to the degradation of the rotor.

\section{Acknowledgement}

This paper was created in the project No. LO1203 "Regional Materials Science and Technology Centre-Feasibility Program" funded by Ministry of Education Youth and Sports of the Czech Republic.

\section{References}

[1] PARK, J., H., TODOROKI, H.: Control of $\mathrm{MgO} \cdot \mathrm{Al}_{2} \mathrm{O}_{3}$ Spinel Inclusions in Stainless Steels. ISIJ Int., vol. 50, No. 10, 2010, pp. 13331346, ISSN 0915-1559.

[2] PARK, J., H., LEE, S., B., GAYE, H., R.: Termodynamics of the Formation of MgO-Al $\mathrm{O}_{3}$-TiO. Metall. Trans. B, vol. 39B, 2008, pp. 853-861, ISSN 1073-5615.

[3] GELDENHUIS, J., M., PISTORIUS, P., C.: Minimisation of Calcium Additions to Low Carbon Steel Grades. Ironmaking and Steelmaking, vol. 27, 2000, p. 442, ISSN 0301-9233.

[4] BURSAK, M., BOKUVKA, O.: Fatigue Properties of Steel with Increased Atmospheric Corrosion Resistance. Communications Scientific Letters of the University of Zilina, vol. 11, No. 1, 2009, pp. 27-30, ISSN 1335-4205.

[5] BURSAK, M., BOKUVKA, O.: Influence of Technological Factors on Fatigue Properties of Steel Sheets. Communications - Scientific Letters of the University of Zilina, vol. 8, No. 4, 2006, pp. 34-37, ISSN 1335-4205.

[6] SAKATA, K.: Technology for Production of Austenite Type Clean Stainless Steel. ISIJ Int., vol. 46, No. 12, 2006, pp. 1795-1799, ISSN 0915-1559.

[7] MAZANCOVA, E, BUZEK, Z., MAZANEC, K.: Evaluation of Influence of Residual Non-ferous Metals on Structural Metallurgical Properties of Steels (in Czech), Hutnicke listy - Metallurgical J., vol. LIII, No. 2, 1998, pp. 19-23, ISSN 0018-8069.

[8] ZHANG, L., THOMAS, B., G.: State of the Art in Evaluation and Control for Steel Cleanliness, ISIJ Int., vol. 43, No. 3, 2003, pp. 271-291, ISSN 0915-1559.

[9] SOJKA, J: The Resistance of Steels to Hydrogen Embrittlement (in Czech), $1^{\text {st }}$ ed., ES VSB-TU : Ostrava, 2007, 108 p., ISBN 978-80248-2187-0. 